\title{
RESPONSABILIDADE SOLIDÁRIA DOS ENTES DA FEDERAÇÃO E "EFEITOS COLATERAIS" NO DIREITO À SAÚDE
}

Solidarity liability of federative entities and "side effects" for the right to health

${ }^{1}$ Universidade do Estado do Rio de Janeiro. Rio de Janeiro/RJ, Brasil.

2 Universidade Santa Úrsula. Rio de Janeiro/RJ, Brasil.

${ }^{3}$ Universidade Católica de Petrópolis. Rio de Janeiro/RJ, Brasil.

Correspondência: Felipe Asensi. E-mail: felipedmı@yahoo.com.br.

Recebido em: 03/08/2015. Revisado em: 06/10/2015. Aprovado em: 23/10/2015. 


\section{RESUMO}

A efetivação judicial do direito à saúde no Brasil suscita avanços e desafios para as políticas públicas. Este artigo analisa dois julgados emanados de acórdãos proferidos no âmbito do Tribunal Regional Federal da $4^{a}$ Região em 2014, que versam sobre a competência comum e solidária dos entes da Federação para o fornecimento de medicamentos. Em ambos os julgados, foi reconhecida a pertinência do pedido autoral e reforçada a tese de que os entes da Federação possuem competência comum e solidária em matéria de saúde. Observa-se, nos julgados em questão, um exemplo comum de aproximação entre o direito e a saúde, de um lado, e de produção de tensões e contradições, de outro. À primeira vista, o reconhecimento da responsabilidade solidária dos entes da Federação pode parecer fortemente positivo sob o prisma do usuário, que terá mais atores possíveis no polo passivo da ação. Porém, sob o prisma da gestão, pode trazer desafios de sobreoneração de um dos entes da Federação em detrimento dos demais. Nesse sentido, a partir dos julgados serão apresentadas as principais regras de competência presentes no âmbito do Sistema Único de Saúde. Em seguida, serão apresentados os principais avanços, limites e desafios no reconhecimento da responsabilidade solidária dos entes da Federação, além de serem expostos alguns "efeitos colaterais" que certas decisões judiciais podem provocar.

\section{Palavras-Chave}

Competência; Direito à Saúde; Judicialização da Saúde; Responsabilidade Solidária.

\section{ABSTRACT}

The judicial enforcement of the right to health in Brazil raises advances and challenges for public policies. This article analyzes two judicial decisions from the $4^{\text {th }}$ Region's Federal Court in 2014 admitting the concurrent and solidary responsibility of federative entities in the supply of medicines. In both decisions, the appeal was allowed and the idea that federative entities have concurrent competence and solidarity in health was reinforced. On the one hand, a common example of interaction between the law and the health is observed in these decisions; on the other, a production of tensions and contradictions is identified. At first glance, the recognition of the solidary responsibility of federative entities may seem strongly positive from the user's perspective, and this will lead to having more users going to courts to claim their right to health. However, from a management perspective, it brings challenges as there will be overpayment of some entities of the federation at the expense of others. In this sense, and based on cases, the main rules of competence currently used in health public policies will be presented. Major advances, limits and challenges of recognizing the solidary responsibility of federative entities as well as some "side effects" that some court decisions may bring will also be discussed.

\section{Keywords}

Competence; Judicialization of Health; Right to Health: Solidary Liability. 


\section{EMENTAS}

ADMINISTRATIVO. FORNECIMENTO DE MEDICAMENTOS OU TRATAMENTO MÉDICO. AGRAVOS RETIDOS. MODIFICAÇÃO DO PEDIDO. RESPONSABILIDADE SOLIDÁRIA DOS ENTES FEDERATIVOS. IMPRESCINDIBILIDADE DO FÁRMACO DEMONSTRADA. SENTENÇA. MANUTENÇÃO. 1. Agravos retidos conhecidos, porquanto requerida expressamente a sua apreciação nas razões de apelação, em conformidade com o disposto no artigo $523, \S 1^{\circ}$, do Código de Processo Civil. 2. Esta Corte tem admitido a inclusão de medicação que não estava inicialmente prescrita, em face de progressão da doença, desde que mantido o objetivo da lide e que o tratamento destine-se à mesma moléstia apontada na inicial, garantindo-se direito à saúde, assegurado pela Constituição Federal, não caracterizando-se, assim, hipótese de emenda à inicial. 3. A ação civil pública é via adequada e o Ministério Público é parte legítima em demanda onde postulado o fornecimento de prestações de saúde pelo poder público, ainda que em favor de pessoa determinada. Precedentes do STJ. 4. A jurisprudência desta Corte firmou-se no sentido da responsabilidade solidária da União, Estados e Municípios nas ações onde se postula fornecimento público de medicamentos ou tratamento médico, o que permite sua propositura contra um, alguns ou todos os entes federativos, conforme opção do interessado. Dessa forma, qualquer um dos entes tem legitimidade ad causam para figurar no polo passivo da demanda. 5. Os requisitos para o fornecimento de medicamentos ou tratamentos médicos não ofertados pelo SUS são (a) comprovação da atual necessidade do medicamento/procedimento; (b) demonstração [de] que o medicamento proposto é insubstituível por outro similar/genérico; (c) a prescrição do respectivo tratamento deverá ser feita, preferencialmente, por médicos credenciados ao SUS e, finalmente, (d) respectiva execução de perícia médico-judicial para delimitar e observar as circunstâncias do caso concreto. 6. No caso, demonstrada a imprescindibilidade do tratamento especificado na proemial, consistente na conjugação da necessidade e adequação dos fármacos e na ausência de alternativa terapêutica, no que mantida a sentença que determinou o fornecimento dos medicamentos pleiteados. 7. Com amparo na prova pericial, viável a substituição do fármaco Lactulona ${ }^{\circledR}$ SP $120 \mathrm{ml}$ pelo seu princípio ativo lactulose, independentemente de marca ou laboratório fabricante. (TRF4, APELREEX 5000569-09.2011.404.7201, Terceira Turma, Relator p/ Acórdão Fernando Quadros da Silva, juntado aos autos em 04/09/2014)

ADMINISTRATIVO. FORNECIMENTO GRATUITO DE MEDICAMENTOS. COMPETÊNCIA PELO VALOR DA CAUSA. JUIZADO ESPECIAL FEDERAL. IMPOSSIBILIDADE DE JULGAMENTO. TEORIA DA CAUSA MADURA. RESPONSABILIDADE SOLIDÁRIA. LEGITIMIDADE PASSIVA DOS ENTES DA FEDERAÇÃO. DO RESSARCIMENTO. DA CONTRACAUTELA E DA MULTA. O valor da presente causa está abarcado pela competência do Juizado Especial Federal, contudo, em havendo óbice para que a lide seja apreciada neste âmbito - não é 
cabível a intervenção de terceiros nos Juizados Especiais Federais -, a Justiça Federal Comum torna-se competente para tal. Estando o feito em ordem para julgamento definitivo, viável a aplicação da teoria da causa madura, prestigiada pelo legislador ordinário no artigo $515, \S 3^{\circ}$, do CPC. A legitimidade passiva de todos os entes federativos para ações que envolvem o fornecimento ou o custeio de medicamento resulta da atribuição de competência comum a eles, em matéria de direito à saúde, e da responsabilidade solidária decorrente da gestão tripartite do Sistema Único de Saúde (arts.23, inciso II, e 198, inciso I, da Constituição Federal). O direito fundamental à saúde é assegurado nos arts. $6^{\circ} \mathrm{e} 196$ da Constituição Federal e compreende a assistência farmacêutica (art. $6^{\circ}$, inc. I, alínea d, da Lei n. 8.080/90), cuja finalidade é garantir a todos o acesso aos medicamentos necessários para a promoção e tratamento da saúde. A questão relativa ao reembolso e/ou cobrança dos custos suportados por determinado ente federativo em decorrência do fornecimento do medicamento pleiteado trata-se de medida a ser resolvida no âmbito administrativo, sem necessidade de intervenção judicial. Diante da condenação ao fornecimento do medicamento é cabível a fixação de contracautela. E possível aplicação de multa diária no caso de retardo ou de descumprimento da decisão, desde que suficiente e compatível com a obrigação, não podendo ser exorbitante ou desproporcional, sob pena de ineficaz e desmoralizadora do próprio comando judicial. (TRF4, AC 5006478-52.2013.404.7204, Quarta Turma, Relatora p/ Acórdão Vivian Josete Pantaleão Caminha, juntado aos autos em 11/09/2014)

\section{Contextualização dos casos}

Os julgados analisados neste artigo são acórdãos proferidos no âmbito do Tribunal Regional Federal da 4a Região (TRF4) em 2014 e versam sobre a competência comum ${ }^{1}$ e a responsabilidade solidária ${ }^{2}$ dos entes da Federação para o fornecimento de medicamentos aos usuários do Sistema Único de Saúde (SUS). Em ambos os julgados, foi reconhecida a pertinência do pedido autoral.

No primeiro caso - APELREEX 5000569-09.2011.404.7201 -, observa-se que a responsabilidade solidária desses entes é premissa do julgamento, admitindo-se a "propositura contra um, alguns ou todos os entes federativos, conforme opção do interessado".

\footnotetext{
${ }^{1} \mathrm{~A}$ competência comum é aquela que pode ser exercida por todos os entes da Federação, respeitando-se os limites constitucionais. 0 artigo 23 da Constituição Federal de 1988 estabelece o rol de competências comuns entre os entes federados, dentre as quais encontra-se a saúde. "Art. 23. É competência comum da União, dos Estados, do Distrito Federal e dos Municípios: [...]ll - cuidar da saúde e assistência pública, da proteção e garantia das pessoas portadoras de deficiência". BRASIL. Constituição da República Federativa do Brasil de 1988. Disponível em: <http://www.planalto.gov.br/ccivil_03/constituicao/ConstituicaoCompilado.htm>. Acesso em: 29 jan. 2016.

${ }^{2}$ Originariamente relacionadas ao Direito Civil e hoje aplicada nas relações entre cidadãos e Estado, nas obrigações solidárias concorrem vários credores, vários devedores ou vários credores e devedores ao mesmo tempo, sendo que cada credor terá o direito de exigir e cada devedor terá o dever de prestar, inteiramente, o objeto da prestação, independentemente de uma ordem de pagamento.
} 
No segundo caso - AC 5006478-52.2013.404.7204-, também se reconheceu a legitimidade passiva de todos os entes para ações que envolvem medicamentos, e isso "resulta da atribuição de competência comum a eles, em matéria de direito à saúde, e da responsabilidade solidária decorrente da gestão tripartite do Sistema Único de Saúde".

De fato, ambos os julgados suscitam questões prementes para a judicialização da saúde no Brasil e que não são triviais. Em regra, denomina-se como "judicialização" o termo que define o movimento de discussão, no campo do direito, dos conflitos político-sociais. Parte-se do princípio de que o Judiciário, "provocado adequadamente, pode ser um instrumento de formação de políticas públicas”, $o$ que confere a esta instituição centralidade no âmbito da garantia de direitos. Tal perspectiva exprime que não somente os atores privilegiados utilizam a via judicial para resolver conflitos políticos - tais como partidos políticos, chefes do Executivo etc. Judicializar relações sociais envolve um processo muito mais amplo, que alça o Judiciário a referencial de resolução de conflitos sociais.

Observa-se, nos julgados em questão, um exemplo comum de aproximação entre o direito e a saúde, de um lado, e de produção de tensões e contradições, de outro. À primeira vista, o reconhecimento da responsabilidade solidária dos entes da Federação pode parecer fortemente positivo sob o prisma do usuário, que terá mais atores possíveis no polo passivo da ação. Porém, sob o prisma da gestão, pode trazer desafios de sobreoneração de um dos entes da Federação em detrimento dos demais. Nesse sentido, uma decisão judicial que reconhece direitos sempre abre novos horizontes de efetivação e, ao mesmo tempo, inaugura novos desafios administrativos e operacionais.

Outro desafio importante dessa aproximação entre o direito e a saúde é uma tendência dos órgãos judiciários de confundir a competência comum com a responsabilidade solidária. Desse modo, tem sido incomum a observância de regras administrativas de repartição de responsabilidades em saúde. Exemplo disso são as poucas referências às chamadas "listas dos SUS", que são relações de medicamentos previstas para cada ente da Federação e que buscam evitar que um ente tenha que custear medicamentos de responsabilidade de outro.

Essas são apenas questões iniciais que nortearão este artigo e que emergem dos casos em análise. No próximo capítulo, serão apresentadas as principais regras de competência presentes no âmbito do SUS. Em seguida, serão apresentados os principais avanços, limites e desafios de se reconhecer a responsabilidade solidária dos entes da Federação, além de serem apresentados alguns "efeitos colaterais" que certas

${ }^{3}$ DALLARI, Sueli Gandolfi; BARBER-MADDEN, Rosemary; TORRES-FERNANDES, Marília; SHUQAIR, Nur; WATANABE, Helena. Advocacia em saúde no Brasil contemporâneo. Revista de Saúde Pública, São Paulo, v. 30, n. 6, 1996. Disponível em: <http://www.scielo.br/pdf/rsp/v30n6/5117.pdf>. http://dx.doi.org/10.1590/S0034-89101996000600014. 
decisões judiciais podem provocar. Por fim, serão delineados os principais horizontes da judicialização da saúde no que concerne à competência e à solidariedade.

\section{SUS e a competência comum}

\section{Competência dos entes da Federação em medicamentos}

A competência comum não quer dizer que todos os entes da Federação têm os mesmos deveres e atribuições. A Constituição de 1988 e as normas posteriores - especialmente a Lei n. 8.080/1990 (Lei Orgânica da Saúde - LOS) - estabelecem atribuições comuns e exclusivas de cada ente, buscando uma previsibilidade administrativa dos deveres de cada um $^{5}$.

A LOS estabelece em seu artigo 15 as atribuições comuns dos três entes da Federação. A relação de atribuições é decisiva para que os diversos governos possam fazer esforços e estratégias comuns para a efetivação da saúde. O efeito prático é a necessidade de os três entes da Federação conjugarem esforços para que efetivem a saúde no Brasil.

Porém, também existem as competências exclusivas de cada ente. A LOS estabelece no artigo 16 o que compete à direção nacional do SUS, que é exercida pela União. O traço mais marcante desta competência é o caráter de coordenação nacional das políticas de saúde a serem desenvolvidas no SUS. A competência federal em matéria de medicamentos é consagrada no Decreto n. 7.508/20116 através da Relação Nacional de Medicamentos Essenciais (Rename). Vejamos:

Art. 25. A Relação Nacional de Medicamentos Essenciais - RENAME compreende a seleção e a padronização de medicamentos indicados para atendimento de doenças ou de agravos no âmbito do SUS.

Parágrafo único. A RENAME será acompanhada do Formulário Terapêutico Nacional - FTN, que subsidiará a prescrição, a dispensação e o uso dos seus medicamentos.

Art. 26. O Ministério da Saúde é o órgão competente para dispor sobre a RENAME e os Protocolos Clínicos e Diretrizes Terapêuticas em âmbito nacional, observadas as diretrizes pactuadas pela CIT.

\footnotetext{
${ }^{4}$ BRASIL. Lei Federal n. 8.080, de 19 de setembro de 1990. Dispõe sobre as condições para a promoção, proteção e recuperação da saúde, a organização e o funcionamento dos serviços correspondentes e dá outras providências. Disponível em: <http://www.planalto.gov.br/ccivil_03/Leis/L8080.htm>. Acesso em: 29 jan. 2016.

${ }^{5}$ Para uma análise minuciosa a respeito das atribuições comuns e específicas de cada ente da Federação, ver ASENSI, Felipe Dutra. Sistema único de saúde. Brasília: Alumnus-Leya, 2015.

${ }^{6}$ BRASIL. Decreto n. 7.508, de 28 de junho de 2011. Regulamenta a Lei $n^{\circ} 8.080$, de 19 de setembro de 1990, para dispor sobre a organização do Sistema Único de Saúde - SUS, o planejamento da saúde, a assistência à saúde e a articulação interfederativa, e dá outras providências. Disponível em: <http://www.planalto.gov.br/ccivil_03/_ato2011-2014/2011/decreto/D7508.htm>. Acesso em: 29 jan. 2016.
} 
Parágrafo único. A cada dois anos, o Ministério da Saúde consolidará e publicará as atualizações da RENAME, do respectivo FTN e dos Protocolos Clínicos e Diretrizes Terapêuticas.

Art. 27. O Estado, o Distrito Federal e o Município poderão adotar relações específicas e complementares de medicamentos, em consonância com a RENAME, respeitadas as responsabilidades dos entes pelo financiamento de medicamentos, de acordo com o pactuado nas Comissões Intergestores.

Art. 28. O acesso universal e igualitário à assistência farmacêutica pressupõe, cumulativamente:

I - estar o usuário assistido por ações e serviços de saúde do SUS; II - ter o medicamento sido prescrito por profissional de saúde, no exercício regular de suas funções no SUS;

III - estar a prescrição em conformidade com a RENAME e os Protocolos Clínicos e Diretrizes Terapêuticas ou com a relação específica complementar estadual, distrital ou municipal de medicamentos; e

IV - ter a dispensação ocorrido em unidades indicadas pela direção do SUS.

$\$ 1^{\circ}$ Os entes federativos poderão ampliar o acesso do usuário à assistência farmacêutica, desde que questões de saúde pública o justifiquem.

$\$ 2^{\circ} \mathrm{O}$ Ministério da Saúde poderá estabelecer regras diferenciadas de acesso a medicamentos de caráter especializado.

Art. 29. A RENAME e a relação específica complementar estadual, distrital ou municipal de medicamentos somente poderão conter produtos com registro na Agência Nacional de Vigilância Sanitária - ANVISA.

A competência estadual em matéria de saúde fica a cargo da secretaria estadual de saúde ou órgão equivalente. A LOS estabelece no artigo 17 o que compete à direção estadual, cabendo a cada estado formular a sua Relação de Medicamentos em complementação à Rename.

A competência municipal em matéria de saúde fica a cargo da secretaria municipal de saúde ou órgão equivalente. A LOS estabelece no artigo 18 o que compete à direção municipal. $\mathrm{O}$ traço mais marcante dessa competência é o caráter de coordenação municipal das políticas de saúde a serem desenvolvidas no SUS, que recebe destaque por conta da descentralização do sistema. Cabe a cada município formular a sua Relação de Medicamentos em complementação às relações estadual e federal.

\section{Regionalização e hierarquização do SUS}

Como os serviços de saúde estão integrados numa rede, nenhum gestor ou profissional de saúde consegue resolver sozinho todas as demandas que são 
submetidas a ele. Isso porque tem que contar com outros serviços de menor ou maior complexidade, tais como exames, tratamentos, medicamentos, procedimentos etc., assim como com outras redes que dão suporte à saúde, tais como a educacional, a de ciência e tecnologia, a de infraestrutura etc.

As características da rede de saúde são a regionalização e a hierarquização. A regionalização valoriza a consideração dos aspectos regionais e locais na prestação dos serviços de saúde, inclusive no que concerne a carências, costumes, valores, crenças e hábitos específicos de cada lugar.

A hierarquização traz a necessidade de que o conjunto de unidades, serviços e ações de saúde trabalhe de maneira articulada, responsabilizando-se pela atenção integral de uma determinada região a partir de diversos recortes territoriais (por exemplo: distrito, microrregião, macrorregião etc.).

O funcionamento da rede é de responsabilidade do gestor do sistema em cada nível, a ser pactuada nas instâncias devidas (por exemplo: comissões bipartites e tripartites, consórcios, mecanismos participativos etc.). Essa pactuação deve observar integralmente os direitos dos cidadãos. Dentre tantos instrumentos existentes de gestão em saúde, três recebem destaque ${ }^{7}$ o Plano Diretor de Regionalização $(\mathrm{PDR})^{8}$, o Plano Diretor de Investimentos em Saúde (PDI) ${ }^{9}$ e a Programação Pactuada Integrada $(\mathrm{PPI})^{10}$. Vale ressaltar ainda a existência do Sistema de Planejamento do SUS (PlanejaSUS) ${ }^{11}$.

Vale também destacar a existência do Pacto de Gestão do SUS, firmado entre os entes da Federação em 2006. O Pacto apresenta as responsabilidades de cada ente, com o propósito de evitar superposições e duplicidades de esforços e de promover uma atuação mais orgânica e coerente entre eles.

${ }^{7}$ BRASIL, Ministério da Saúde. SUS: instrumentos de gestão em saúde. Brasília: Ministério da Saúde, 2002. ${ }^{8} \mathrm{O}$ PDR é o instrumento de ordenamento do processo de regionalização dos serviços de saúde. Ele deve ser elaborado buscando o planejamento integrado, de modo a valorizar a territorialidade na identificação de prioridades de atuação. Com esses parâmetros, devem-se otimizar os recursos disponíveis para o alcance dos objetivos pactuados. O PDR exerce uma função importante de redução das desigualdades sociais e territoriais ao buscar ampliar o acesso dos usuários a todos os níveis de atenção à saúde.

${ }^{9} \mathrm{O}$ PDI evidencia e qualifica os investimentos necessários para atender às prioridades pactuadas no PDR, buscando ampliar decisivamente a sustentação financeira das ações e dos serviços de saúde existentes, além de compatibilizar com os objetivos e metas futuros para manter a resolutividade e funcionalidade do sistema.

${ }^{10} \mathrm{~A}$ PPI é o instrumento de programação e alocação de recursos da assistência em saúde. Esse instrumento envolve diversos elementos, tais como a definição, negociação e formalização dos pactos intergestores. Seu objetivo principal consiste em estabelecer os fluxos assistenciais das redes regionalizadas e hierarquizadas de serviços, assim como os limites financeiros destinados a cada município e mecanismos de repasse de verbas.

${ }^{11}$ O PlanejaSUS pressupõe que cada ente da Federação realize seu planejamento em saúde, articulando-se com o objetivo de fortalecer os objetivos e diretrizes do SUS. Os instrumentos básicos desse planejamento são: (a) o plano de saúde, que apresenta as intenções e os resultados a serem buscados em quatro anos através de objetivos, diretrizes e metas; (b) a programação anual de saúde, que apresenta as iniciativas a serem implementadas em determinado ano, considerando-se o plano de saúde; e (c) e o relatório de gestão, que apresenta os resultados alcançados com a programação anual de saúde e orienta eventuais mudanças e redirecionamentos. Vale dizer que os três instrumentos devem ser compatíveis com o Plano Plurianual, a Lei de Diretrizes Orçamentárias e a Lei Orçamentária Anual. 
Muito além de definir diretrizes gerais, o pacto tem a preocupação de avançar na descentralização do SUS, respeitando as diversidades locais e regionais. Não é por acaso que busca intensificar a territorialização da saúde para a organização do SUS, inclusive com regiões sanitárias e colegiados de gestão. O pacto também explicita as diretrizes para o sistema de financiamento público tripartite ao buscar critérios de alocação equitativa dos recursos, reforçar os mecanismos de transferência de recursos, integrar o financiamento e estabelecer relações contratuais entre os entes federativos.

\section{Desafios da responsabilidade solidária}

Considerando as competências dos entes da Federação no âmbito do SUS e, em especial, no fornecimento e custeio de medicamentos, observa-se que não se trata de algo simplesmente abstrato. Em verdade, nesses 25 anos de vigência do SUS, foram estabelecidos diversos instrumentos normativos para conferir maior concretude à responsabilidade de cada ente.

Obviamente, seria ingênuo afirmar que todas as atribuições estão claramente definidas e que não há espaço para imprecisões, omissões ou contradições. Porém, mesmo assumindo essas imprecisões, não se pode ignorar que houve um avanço institucional na repartição de competências, especialmente no que concerne a medicamentos.

Por conta das especificidades das políticas, dos programas, das ações e dos serviços de saúde, é comum que os profissionais do direito não tenham o controle normativo de todos os aspectos institucionais de repartição de competências. Observa-se uma tendência de as decisões judiciais serem mais principiológicas e se aterem às normas gerais da Constituição de 1988. Porém, em alguns casos, a desconsideração das competências regulamentadas em leis ordinárias e demais instrumentos normativos pode conferir uma relativa instabilidade decisória.

Isso evidencia que o Judiciário não é isento de desafios internos para lidar com o volume processual cada vez mais intenso em saúde. Um dos principais desafios refere-se à cultura interna dos magistrados, que pode ser caracterizada pela fraqueza da vinculação decisória e pela forte independência funcional. Segundo Taylor,

[...] a fraqueza de precedentes vinculantes também polemiza os objetivos extensivos do formalismo com o sistema de civil law brasileiro. O número de leis, combinado com a falta da estabilidade das decisões (stare decisis), significa que as chances de uma interpretação do direito pode variar de juiz para juiz. Casos similares podem, então, ser legitimamente decididos, entre os limites os institucionais, de múltiplas formas. Isso permite um cenário em que o particularismo não é apenas possível, e que o juiz está longe de ser um expert e, mais ainda, de um intérprete. Isso também resulta, sistematicamente, num aglomerado de casos 
que surgem de uma variedade de interpretações possíveis nos vários níveis do sistema de tribunais ${ }^{12}$.

No limite, o juiz brasileiro pode emanar decisões das mais diversas e, em alguns casos, reconfigurar as normas jurídicas para atender a determinadas interpretações a respeito dos direitos.

É importante ressaltar que as regras de competência não podem ser confundidas com a previsão normativa de responsabilidade solidária. A competência diz respeito à repartição administrativa de atribuições entre os três entes da Federação prevista nas relações de medicamentos, sendo discutível se essas relações são taxativas ou exemplificativas. A responsabilidade diz respeito ao dever jurídico de cada ente da Federação de, em conjunto ou isoladamente, efetivar um determinado direito específico.

Nesse sentido, por mais que sejam garantistas e reconheçam o direito à saúde dos cidadãos, as decisões similares às analisadas neste artigo podem eventualmente produzir três "efeitos colaterais" ao vincularem a competência comum em saúde à responsabilidade solidária.

Em primeiro lugar, nota-se que a ausência de clareza sobre a repartição de competências em saúde entre os profissionais do direito pode produzir um efeito colateral. Enquanto direito social, a saúde é permeada por diversas leis, atos normativos, decretos, resoluções, recomendações e outros instrumentos jurídicos que visam a tornar mais densa a sua institucionalidade. Porém, na medida em que os profissionais do direito tendem a ter uma visão abstrata do direito à saúde e ancorada nos princípios e na Constituição de 1988, observa-se uma tendência de ignorarem as regras infraconstitucionais que se desenvolveram no âmbito do Legislativo e da própria gestão, inclusive pactuadas com os mecanismos de controle social do SUS.

Em segundo lugar, ao se reconhecer a responsabilidade solidária entre os entes da Federação, observa-se uma tendência de sobreonerar os municípios em relação aos estados e à União ${ }^{13}$. A esse respeito, Asensi e Pinheiro salientam que isso pode ocorrer pelos seguintes motivos: (a) relativo desconhecimento dos profissionais do direito a respeito das atribuições de cada ente da Federação em matéria de saúde; (b) a atuação das defensorias públicas tende a se desenvolver de maneira mais sólida nas capitais e com foco na atuação municipal em saúde; e (c) em razão da descentralização da saúde, os municípios passam a ser concebidos como principais responsáveis por efetivar demandas judiciais pelos profissionais do direito. Com isso, observa-se uma

\footnotetext{
${ }^{12}$ TAYLOR, Matthew. Citizens against the State - the riddle of high impact, low functionality courts in Brazil. Brazilian Journal of Political Economy, v. 25, n. 4, p. 418 - 438, 2005. Disponivel em: <http://www.scielo.br/pdf/rep/ v25n4/28292.pdf>. http://dx.doi.org/10.1590/S0101-31572005000400007. p. 433. (Tradução do autor)

${ }^{13} \mathrm{~A}$ respeito da tendência de se sobreonerar os municípios em relação aos estados e à União, ver o relatório de Asensi e Pinheiro a respeito da judicialização da saúde no Brasil, em parceria com o Conselho Nacional de Justiça. ASENSI, Felipe;PINHEIRO, Roseni. Judicialização da saúde no Brasil. Brasília: CNJ, 2015.
} 
tendência de "municipalização das demandas", seja porque são de responsabilidade do município, seja porque são de responsabilidade de outros entes da Federação e o município responderá em função da responsabilidade solidária. Vale também observar uma tendência de interpretação pelos tribunais de que as "listas de medicamentos" mencionadas no tópico anterior são meramente exemplificativas, o que pode suscitar demandas municipais de medicamentos não constantes das listas do SUS.

Em terceiro lugar, observa-se uma fragilidade dos mecanismos de compensação financeira por demandas judiciais que um ente da Federação suportou e que seriam de responsabilidade de outro ente. A competência comum não afasta a repartição de atribuições administrativas que os entes pactuam entre si nos instrumentos de gestão próprios do SUS. Porém, as leis específicas da saúde que tratam de orçamento - Constituição de 1988, LOS, Lei n. 8.142/1990 14 e Lei Complementar n. $141 / 2012^{15}$ - não especificam as condições e os procedimentos de ressarcimento de um ente em relação a demandas judiciais pelas quais respondeu e que deveriam ser custeadas e fornecidas por outro ente.

Considerando esses "efeitos colaterais", é importante considerar os desafios oriundos da responsabilidade solidária em matéria de saúde e em que medida podem produzir desigualdades e ineficiências sistêmicas na prestação dos serviços de saúde. Obviamente, são "efeitos colaterais" que podem ocorrer, mas não necessariamente. De todo modo, em função de uma relativa indiferença dos julgados em relação à distinção entre as regras de competência e de responsabilidade, é possível que tenhamos situações discrepantes na prestação dos serviços de saúde e na continuidade das políticas públicas. Não se pode ignorar a densidade normativa e institucional das ações e dos serviços de saúde, sendo fundamental que as decisões judiciais se qualifiquem ainda mais para além dos princípios e da Constituição de 1988.

\section{Considerações finais}

O protagonismo das instituições jurídicas - e, em especial, do Judiciário - não esteve isento de contradições no Brasil e isso é um processo compreensível. Exames, tratamentos e medicamentos, principalmente se forem excepcionais, trazem em seu bojo, quando deferidos judicialmente, a necessidade de fornecimento sem obrigatoriamente

\footnotetext{
${ }^{14}$ BRASIL. Lei Federal n. 8.142, de 28 de dezembro de 1990. Dispõe sobre a participação da comunidade na gestão do Sistema Único de Saúde (SUS) e sobre as transferências intergovernamentais de recursos financeiros na área da saúde e dá outras providências. Disponível em: <http://www.planalto.gov.br/ccivil_03/LEIS/L8142.htm>. Acesso em: 29 jan. 2016.

${ }^{15}$ BRASIL. Lei Complementar n. 141, de 13 de janeiro de 2012. Regulamenta o $\S 3^{\circ}$ do art. 198 da Constituição Federal para dispor sobre os valores mínimos a serem aplicados anualmente pela União, Estados, Distrito Federal e Municípios em ações e serviços públicos de saúde; estabelece os critérios de rateio dos recursos de transferências para a saúde e as normas de fiscalização, avaliação e controle das despesas com saúde nas 3 (três) esferas de governo; revoga dispositivos das Leis $n^{\circ}$ 8.080, de 19 de setembro de 1990, e 8.689, de 27 de julho de 1993; e dá outras providências. Disponível em: <http://www.planalto.gov.br/ccivil_03/leis/LCP/Lcp141.htm>. Acesso em: 29 jan. 2016.
} 
haver um planejamento de governo. Independentemente de isso ser bom ou ruim, o fato é que a judicialização da saúde no Brasil tem reconfigurado drasticamente as responsabilidades dos entes da federação para o estabelecimento de políticas públicas que atendam aos critérios de universalidade, integralidade e descentralização.

Sem dúvida, os julgados analisados consolidam o direito à saúde e aprofundam a democratização do acesso à saúde no Brasil. Porém, podem produzir efeitos colaterais relacionados à associação linear entre competência comum e responsabilidade solidária. Em matéria de medicamentos, por exemplo, a repartição de atribuições é bastante clara e objetiva, havendo ainda margem para a inclusão de medicamentos não constantes das listas do SUS.

À medida que o Judiciário se fortalece no Brasil e assume o protagonismo na efetivação do direito à saúde, estaria este Poder necessariamente efetivando o SUS? Não seria o caso de incluir o Judiciário nesse Pacto pela Gestão do SUS, de modo a reduzir os "efeitos colaterais" das decisões? O que se observa, na verdade, são desafios que se apresentam na relação entre Estado, sociedade e instituições jurídicas no processo de efetivação do direito à saúde e de consolidação do SUS.

\section{Referências}

ASENSI, Felipe Dutra. Sistema único de saúde. Brasília: Alumnus-Leya, 2015.

; PINHEIRO, Roseni. Judicialização da saúde no Brasil. Brasília: CNJ, 2015.

BRASIL, Ministério da Saúde. SUS: instrumentos de gestão em saúde. Brasília: Ministério da Saúde, 2002.

DALLARI, Sueli Gandolfi; BARBER-MADDEN, Rosemary; TORRES-FERNANDES, Marília; SHUQAIR, Nur; WATANABE, Helena. Advocacia em saúde no Brasil contemporâneo. Revista de Saúde Pública, São Paulo, v. 30, n. 6, 1996. Disponível em: <http://www.scielo.br/pdf/rsp/ v30n6/5117.pdf>. http://dx.doi.org/10.1590/S0034-89101996000600014.

TAYLOR, Matthew. Citizens against the State - the riddle of high impact, low functionality courts in Brazil. Brazilian Journal of Political Economy, v. 25, n. 4, p. 418-438, 2005. Disponível em: <http://www.scielo.br/pdf/rep/v25n4/28292.pdf>. http://dx.doi.org/10.1590/S0101-31572005000400007.

Felipe Asensi -Pós-Doutor em Direito pela Universidade do Estado do Rio de Janeiro; doutor em Sociologia pelo Instituto de Estudos Sociais e Políticos da Universidade do Estado do Rio de Janeiro; mestre em Sociologia pelo Instituto Universitário de Pesquisas do Rio de Janeiro. Professor Adjunto da Universidade do Estado do Rio de Janeiro, da Universidade Santa Úrsula e da Universidade Católica de Petrópolis. Advogado. Rio de Janeiro/RJ, Brasil. E-mail: felipedml@yahoo.com.br. 